\title{
Exercise portrayal in children's television programs: analysis of the UK and Irish programming
}

\author{
Paul Scully' \\ Orlaith Reid' \\ Alan P Macken ${ }^{1-3}$ \\ Mark Healy ${ }^{4}$ \\ Jean Saunders ${ }^{4}$ \\ Des Leddin ${ }^{3,5}$ \\ Walter Cullen ${ }^{3}$ \\ Colum P Dunne ${ }^{3}$ \\ Clodagh S O'Gorman ${ }^{1-3,5}$ \\ 'The Children's Ark, University \\ Hospital Limerick, Limerick, ${ }^{2}$ National \\ Children's Research Centre, Dublin, \\ ${ }^{3}$ Centre for Interventions in Infection, \\ Inflammation \& Immunity (4i), \\ Graduate Entry Medical School, \\ ${ }^{4} \mathrm{C}$-Star, University of Limerick, \\ Limerick, Ireland; ${ }^{5}$ Department of \\ Medicine, Dalhousie University, \\ Halifax, Canada
}

This article was published in the following Dove Press journal: Diabetes, Metabolic Syndrome and Obesity:Targets and Therapy 23 September 2016

Number of times this article has been viewed

Background: Television watching is obesogenic due to its sedentary nature and programming content, which influences children. Few studies have examined exercise placement within children-specific programming. This study aimed to investigate the frequency and type of exercise placement in children-specific television broadcasts and to compare placements on the UK and Irish television channels.

Methods: Content analysis for five weekdays' worth of children-specific television broadcasting totaling 82.5 hours on both the UK (British Broadcasting Corporation) and Irish (Radió Teilifís Éireann) television channels was performed. For the purposes of comparing the UK and Irish placements, analysis was restricted to programming broadcast between 6 am and $11.30 \mathrm{am}$. Exercise placements were coded based on type of activity, activity context, activity motivating factors and outcome, and characters involved.

Results: A total of 780 cues were recorded during the total recording period. A wide variety of sports were depicted, but dancing-related cues were most commonly seen ( $n=163,23.3 \%)$, with the majority of cues being of mild $(n=365,65.9 \%)$ or moderate $(n=172,31.0 \%)$ intensity. The majority of cues were associated with a positive outcome $(n=404,61.4 \%)$, and social motivations were most commonly seen $(n=289,30.3 \%)$. The Irish and the UK portrayals were broadly similar. Conclusion: This study highlights the wide variety of sports portrayed and the active effort undertaken by television stations to depict physical exercise and recreation in a positive light.

Keywords: television, exercise, children, obesity

\section{Introduction}

Contributors to childhood obesity include more sedentary time and less active time, excessive portion sizes, and poorer choices in food consumed. ${ }^{1}$ Obesity is a risk factor for development of metabolic syndrome, and people with the syndrome are two to three times as likely to have a heart attack or stroke and five times as likely to develop type 2 diabetes compared with people without the syndrome. ${ }^{2}$ This condition is appearing with increasing frequency in children and adolescents, due to the growing obesity epidemic within the young population. ${ }^{3}$ As components of the metabolic syndrome tend to track from childhood to adulthood, primary prevention of their development or early reversal of their presence in childhood is of paramount importance. ${ }^{4}$

Time spent watching television is a well-described contributor to childhood obesity, ${ }^{5-8}$ being associated with greater periods of inactivity and exposure to food advertising and products. ${ }^{9,10}$ The prevalence of overweight children is strongly positively correlated with hours of television viewed. ${ }^{8,11}$ A linear dose-response relationship has
Correspondence: Clodagh S O'Gorman The Children's Ark, University Hospital Limerick, Limerick, Ireland

Tel +35361234756

Fax +353 6I 233778

Email clodagh.ogorman@ul.ie 
been found for television watching and childhood obesity, and the risk increased by $13 \%$ for each hour per day increment in television watching. This observation was seen in both boys and girls. ${ }^{12}$ Additionally, a prospective study showed that both childhood and adult television viewing times were significantly associated with higher body mass and lower cardiorespiratory fitness at the age of 32 years. ${ }^{13}$ The American Academy of Pediatrics recommends that children older than 2 years should watch no more than 2 hours of noneducational television per day. ${ }^{14}$ Recent evidence suggests that children aged 6-11 years watch television as much as 24.5 hours per week, which is $\sim 10$ hours more than the recommended watching. ${ }^{15}$

Many studies have examined the portrayal of food within advertisements and to a much lesser extent in children's programming, but few have examined the portrayal of exercise and physical activity. ${ }^{9-15}$ Studies of the level of coverage and the attitudes toward physical activity in prime time television in the US between 1970 and 2001 suggested that news networks aired only three to four physical activity-related broadcasts annually. ${ }^{16}$ However, these broadcasts almost always portrayed positive benefits associated with physical activity. A study examining food advertisements directed at African-American children found that only $9.4 \%$ of the advertisements contained physical activity-related content. ${ }^{17}$ A study examining embedded commercials and reality entertainment programming on motivations and efficacy to exercise and consuming a healthy diet showed that perceived realism of the health-oriented reality program generated greater confidence to eat more healthily, as well as greater motivation to exercise, thus supporting the assertion that reality programming may potentiate positive health behaviors. ${ }^{18}$ A further study examining audience exposure, beliefs, and reactions to media portrayals of physical activity showed that most respondents could only recall media coverage of physical activity with prompting, while the messages most readily recalled were the health risks of inactivity, especially obesity, and the necessity of keeping active. ${ }^{19}$ Additionally, physical activity was regarded as a matter of personal volition, or for children, parental responsibility. ${ }^{19}$

From a media perspective, it has previously been shown that food companies actively target children through the use of sports images on retail packaging, including portrayals of cartoon characters engaging in physical activity, and also through television commercials. ${ }^{20}$ Children, particularly younger children, are more susceptible and have lower cognitive defenses against television marketing, ${ }^{21,22}$ while health-related behaviors such as eating habits and physical activity patterns develop early in life and often extend into adulthood. ${ }^{23}$ Such messages and portrayals, therefore, may impact a child's preferences for food and beverages and also influence preferences for recreation and physical activities. Previous research has largely concentrated on programming within the US. ${ }^{17,20,23,24}$ Encouragingly, more recently it has been shown that the number of food advertisements viewed by children is decreasing. ${ }^{25}$

Our objectives were to examine the portrayal of exercise and physical activity on children-specific programming broadcast within Ireland and the UK. We studied public broadcast channels only as these are nonprofit in nature with a mission statement to offer a positive and trusted voice in broadcasting as well as informing, educating, and empowering audiences. ${ }^{26,27}$

\section{Methods}

\section{Program recording}

Content analysis of programs broadcast on UK (British Broadcasting Corporation [BBC]) and Irish (Radió Teilifís Éireann [RTE]) children's television programs was conducted, including 5 weekdays of programs broadcast during children-specific television strands. Programs were recorded in July 2010 and October 2010, totaling 82.5 hours. Programming on RTE took place between 6 am and 5 pm daily, while programming on BBC took place between 6 am and $11.30 \mathrm{am}$. Outside of these times, programming was directed at a general audience and not specifically at children. For the purpose of comparing the UK and Irish broadcasts, only programs broadcast between 6 am and 11.30 am were included. The country of origin and year of production of individual programs were also recorded. This study was observational, looking at television programming, and did not involve human subjects; thus, ethical approval was not required. Recorded programs were viewed by two investigators (PS and OR).

\section{Data coding}

\section{Exercise placement}

The recorded programs were viewed, and cues were coded into data collection sheets. An exercise cue was defined as a portion within a scene where a sport or activity was undertaken. Exercises were subclassified into 21 different categories as shown in Table 1. Cues were also coded according to whether the portrayal was visual, verbal, or a combination of visual-verbal. Each exercise cue was coded only once for a given scene or for a given character per scene. Cue duration was recorded. Exercise cues presented in the 
Table I Exercise associated with each individual cue

\begin{tabular}{|c|c|c|c|c|}
\hline Cue type & Overall $(n=699)$ & RTE $(n=203)$ & BBC $(n=278)$ & $\chi^{2} / t$-test \\
\hline \multicolumn{5}{|l|}{ Exercise } \\
\hline Exercise & $29(4.1 \%)$ & 15 (7.4\%) & $10(3.6 \%)$ & $3.42(P=0.09)$ \\
\hline Informal & $74(10.6 \%)$ & $16(7.9 \%)$ & 42 (15.1\%) & $5.78(P=0.02)^{*}$ \\
\hline Soccer & $60(8.6 \%)$ & 16 (7.9\%) & $29(10.4 \%)$ & $0.90(P=0.43)$ \\
\hline Basketball & $23(3.3 \%)$ & 9 (4.4\%) & $6(2.2 \%)$ & $2.01(P=0.19)$ \\
\hline Swimming & 70 (10.0\%) & $21(10.3 \%)$ & 31 (11.2\%) & $0.08(P=0.88)$ \\
\hline Tennis & $16(2.3 \%)$ & $5(2.5 \%)$ & $4(1.4 \%)$ & $0.67(P=0.50)$ \\
\hline Athletics & $30(4.3 \%)$ & 9 (4.4\%) & $15(5.4 \%)$ & $0.23(P=0.68)$ \\
\hline Rugby & $6(0.9 \%)$ & $2(1.0 \%)$ & 0 & $2.75(P=0.18)$ \\
\hline Hurling ${ }^{\mathrm{a}}$ & $21(3.0 \%)$ & $10(4.9 \%)$ & 0 & $13.9(P<0.00 \mid)^{* *}$ \\
\hline Gaelic football ${ }^{\mathrm{a}}$ & $14(2.0 \%)$ & $8(3.9 \%)$ & 0 & II.I $(P<0.001)^{* *}$ \\
\hline Golf & $8(1.1 \%)$ & $3(1.5 \%)$ & 0 & $4.13(P=0.08)$ \\
\hline Dancing & $163(23.3 \%)$ & 28 (I3.8\%) & $76(27.3 \%)$ & $12.7(P<0.001)^{* *}$ \\
\hline Cycling & 55 (7.9\%) & $22(10.8 \%)$ & 18 (6.5\%) & $2.93(P=0.09)$ \\
\hline American football & $6(0.9 \%)$ & $4(2.0 \%)$ & 0 & $5.52(P=0.03)^{*}$ \\
\hline Baseball & $17(2.4 \%)$ & $6(3.0 \%)$ & $6(2.2 \%)$ & $0.31(P=0.57)$ \\
\hline Skateboarding & $22(3.1 \%)$ & $4(2.0 \%)$ & I 4 (5.0\%) & $3.06(P=0.09)$ \\
\hline Archery & $6(0.9 \%)$ & $4(2.0 \%)$ & 0 & $5.52(P=0.03)^{*}$ \\
\hline Boxing & 7 (1.0\%) & $4(2.0 \%)$ & 0 & $5.52(P=0.03)^{*}$ \\
\hline Gymnastics & $22(3.1 \%)$ & $6(3.0 \%)$ & $10(3.6 \%)$ & $0.15(P=0.80)$ \\
\hline Yoga & $10(1.4 \%)$ & $0(0 \%)$ & $10(3.6 \%)$ & $7.45(P=0.006)^{* * *}$ \\
\hline Other & 40 (5.7\%) & II (5.4\%) & 7 (2.5\%) & $2.74(P=0.14)$ \\
\hline \multicolumn{5}{|l|}{ Cue duration (s) } \\
\hline Overall & $33.1 \pm 2.5$ & $28.1 \pm 3.5$ & $34.7 \pm 2.5$ & $P=0.12$ \\
\hline
\end{tabular}

Notes: The comparison undertaken is between RTE and BBC programming during the recording period where both channels depicted children-specific programming $(6 \mathrm{am}-\mathrm{II} .30 \mathrm{am})$. Values given are frequencies (total relative \%). Numeric data are expressed as mean $\pm S E M$. The level of significance is represented as $* P<0.05$, $* * P<0.00 \mathrm{I}$, and $* * * P<0.01$. ${ }^{\mathrm{a}} \mathrm{A}$ team-based field game peculiar to Ireland and played at all age levels.

Abbreviations: RTE, Radió Teilifís Éireann; BBC, British Broadcasting Corporation; SEM, standard error of the mean.

background were coded. The coding scheme generated was based on variables related to children-specific programming from previous peer-reviewed publications. ${ }^{28,29}$

\section{Exercise context and intensity}

Cue context was noted, including if the activity was formal (part of a competition or structured training session), informal, or involved a team sport. The intensity of the exercise was rated as mild, moderate, or intense, on the basis of subjective, perceived effort of the characters involved.

\section{Characters}

Characters associated with the cue were recorded: human, animated human, or animated characters. If human, estimates of age, ethnicity, and weight status were documented.

\section{Cue motivation and outcome}

Motivations related to the cue were recorded under several classifications, and multiple motivations were recorded under the same cue if necessary. Motivations were further subclassified as positive (social/celebratory, excitement, reward), negative (punishment), or neutral (health, competitive). The outcome of the cue was also coded as positive, negative, or neutral. A positive outcome included enjoyment, winning a race or prize, aid to other people, or feeling better following the cue. Negative outcomes included pain or personal harm, disgust or physical grimacing or crying, vomiting, or harm to other people.

\section{Statistical analysis}

Data collection was piloted and reviewed after 1 day of sample programming, to allow for detailed study and further discussion of any ambiguous cues or placements. Each program was then coded independently and in duplicate by departmental staff members (PS and OR). Where disagreements arose, consensus was achieved with the principal supervisor (CSOG). Interrater reliability was measured, and pilot data collection continued and data were reviewed at 1 hour duration until kappa reliability of 0.80 was achieved for each variable. Data analysis was performed using SPSS Version 20. Exercise placements were analyzed and compared between the UK and Irish programming using the $\mathrm{c}^{2}$ test. Duration of cue was recorded, and mean values were compared using an independent $t$-test. Differences were considered significant at $P<0.05$. 


\section{Results \\ Overall recordings}

\section{Recording statistics}

Over the 82.5 hours recording period, a total of 780 (BBC $=323$; RTE $=457$ ) exercise cues were recorded, averaging one cue every 6.3 minutes, with total exercise cues amounting to 6.38 hours ( $7.73 \%$ of total recording period) and averaging 33.1 seconds per cue. A total of 55 individual programs, produced in nine countries, were recorded. The US was the most common country of origin (39.5\%), followed by the UK $(23.2 \%)$ and Ireland (15.9\%). The year of production ranged from 1955 to 2010: 66\% of recordings were produced between 2004 and 2010. Broadcast of filler advertisements between the individual programs accounted for $17.2 \%$ of the cues (Table 1 ).

\section{Exercise types}

In total, 21 exercise groups were depicted during the recording period, most commonly dancing cues $(23.3 \%)$, followed by informal play (10.6\%) and swimming cues (10.0\%). Formal exercise settings accounted for $8.3 \%$ of cues and team sports $9.3 \%$. The intensity of the cues was mild in $65.9 \%$ of cases, moderate in $31.0 \%$, and intense in $3.1 \%$ (Tables 1 and 2).

\section{Cue usage}

Visual cues accounted for $30.8 \%$, while $24.4 \%$ were verbal and $44.8 \%$ visual-verbal. Almost all cues occurred in the program foreground (Table 2).

\section{Characters}

Human characters accounted for $53.0 \%$ of cues, animated characters for $25.5 \%$, and animated human characters for $7.3 \%$. Male characters were involved in $40.7 \%$ of cues, a major character in $84.5 \%$, and a character "goodie" in $97.2 \%$. Adults were the most common age group involved with cues $(32.0 \%)$, followed by children (30.3\%) and teens (18.1\%; Table 2$)$.

\section{Outcome and motivation}

The most common motivating factor was social $(30.3 \%)$, followed by excitement (29.1\%). Motivation was positive in $74.9 \%$ of exercise cues, neutral in $23.2 \%$, and negative in $1.9 \%$. Cue outcome was positive in $61.4 \%$, negative in $12.9 \%$, and neutral in $25.7 \%$ (Table 3 ).

\section{Channel comparison summary}

\section{Recording statistics}

A comparison was made between BBC and RTE children's programming on 5.5 hours of morning programming over a 5-day period. In total, $278 \mathrm{BBC}$ and $203 \mathrm{RTE}$ cues were recorded, with a new cue every 5.1 minutes for BBC and 3.6 minutes for RTE. The total recorded time involving exercise cues was 2.7 hours for BBC and 3.7 hours for RTE programs, with an average of 34.7 seconds per cue for $\mathrm{BBC}$ and 28.1 seconds for RTE television programming $(P=0.12)$. For both BBC and RTE television programming, broadcast of exercise-specific filler advertisements between advertisements showed most exercise cues, accounting for $13.0 \%$ and $24.3 \%$ of cues, respectively (Table 1 ).

\section{Exercise types}

Dancing cues were most commonly seen on both BBC (27.3\%) and RTE television (13.8\%). For BBC programs, informal exercises (15.1\%) and swimming cues (11.2\%) were next most popular. For RTE programs, cycling $(10.8 \%)$ and swimming (10.3\%) were next most popular. BBC and RTE had similar proportions of cues for formal sports $(P=0.18)$ and team sports $(P=0.16)$. BBC had more mild intensity exercise cues $(P<0.001)$, while RTE television had statistically higher levels of moderate $(P<0.001)$ and intense $(P=0.001)$ exercise cues (Tables 1 and 2).

\section{Cue usage}

BBC had more visual cues (BBC 40.6\%; RTE 20.9\%; $P<0.001$ ), and RTE had more verbal cues (BBC 9.7\%; RTE $35.3 \% ; P<0.001$ ) cues (Table 2 ).

\section{Characters}

The RTE cues had significantly more involvement of human characters (BBC 15.5\%; RTE 80.8\%; $P<0.001$ ), and the $\mathrm{BBC}$ cues had more involvement of animated characters (BBC 52.2\%; RTE 8.2\%; $P<0.001$ ). The RTE cues were also associated with a greater proportion of male sex (BBC $29.1 \%$; RTE 49.2\%; $P<0.001$ ) and female sex (BBC 4.3\%; RTE $24.9 \% ; P<0.001)$ characters. The UK cues had greater number of adult character involvement (BBC 52.2\%; RTE $25.7 \% ; P<0.001$ ), with RTE programming having a higher proportion of teenage characters (BBC 0.0\%; RTE $18.0 \%$; $P<0.001$; Table 2).

\section{Outcome and motivation}

On BBC programming, social motivating factors (37.7\%) were most common, followed by excitement $(27.0 \%)$ and competitive (only $7.1 \%$ ) factors. For RTE programming, competitive factors $(24.0 \%)$ were most common, followed by social $(22.9 \%)$ and excitement $(20.6 \%)$ factors. Irish television exercise cues were statistically higher for reward $(P<0.001)$, punishment $(P=0.01)$, and competitive $(P<0.001)$ 
Table 2 Comparison of type, context, and character associated with each cue

\begin{tabular}{|c|c|c|c|c|}
\hline Cue characteristics & Overall $(n=699)$ & RTE $(n=203)$ & $\operatorname{BBC}(n=278)$ & $\chi^{2}$ \\
\hline \multicolumn{5}{|l|}{ Cue type } \\
\hline Visual & $214(30.8 \%)$ & $42(20.9 \%)$ & $113(40.6 \%)$ & $20.8(P<0.00 I)^{*}$ \\
\hline Verbal & $169(24.4 \%)$ & 71 (35.3\%) & $27(9.7 \%)$ & $47.0(P<0.001)^{*}$ \\
\hline Combined visual/verbal & $311(44.8 \%)$ & $88(43.8 \%)$ & $138(49.6 \%)$ & $1.61(P=0.23)$ \\
\hline Foreground & $689(99.6 \%)$ & 199 (99.0\%) & $278(100 \%)$ & $2.77(P=0.18)$ \\
\hline \multicolumn{5}{|l|}{ Cue context } \\
\hline Formal & $58(8.3 \%)$ & $21(10.3 \%)$ & $19(6.8 \%)$ & $\mathrm{I} .89(P=0.18)$ \\
\hline Team & $65(9.3 \%)$ & $26(12.8 \%)$ & $15(5.4 \%)$ & $2.13(P=0.16)$ \\
\hline Cue intensity & & & & $0.11(P=0.79)$ \\
\hline Mild & $365(65.9 \%)$ & 57 (44.5\%) & $24 \mid(86.7 \%)$ & $79.8(P<0.001)^{*}$ \\
\hline Moderate & $172(31.0 \%)$ & $62(48.4 \%)$ & $35(12.6 \%)$ & $61.9(P<0.001)^{*}$ \\
\hline Severe & $17(3.1 \%)$ & $9(7.0 \%)$ & $2(0.7 \%)$ & $13.3(P=0.00 \mid)^{* *}$ \\
\hline \multicolumn{5}{|l|}{ Characters } \\
\hline Human & 349 (53.0\%) & I 47 (80.8\%) & 43 (I5.5\%) & $193(P<0.001)^{*}$ \\
\hline Animated human & $48(7.3 \%)$ & $18(9.9 \%)$ & $16(5.8 \%)$ & $2.75(P=0.10)$ \\
\hline Animated & $168(25.5 \%)$ & $15(8.2 \%)$ & 145 (52.2\%) & $93.5(P<0.00 \mathrm{I})^{*}$ \\
\hline Combination of all three above & $93(14.1 \%)$ & $2(1.1 \%)$ & $74(26.6 \%)$ & $51.9(P<0.001)^{*}$ \\
\hline \multicolumn{5}{|l|}{ Sex } \\
\hline Male & $267(40.7 \%)$ & 89 (49.2\%) & $81(29.1 \%)$ & $18.8(P<0.00 \mid)^{*}$ \\
\hline Female & $88(13.4 \%)$ & 45 (24.9\%) & $12(4.3 \%)$ & $42.6(P<0.00 I)^{*}$ \\
\hline Combined male/female & 301 (45.9\%) & $47(26.0 \%)$ & $185(66.5 \%)$ & $72.2(P<0.001)^{*}$ \\
\hline Major character & $554(84.5 \%)$ & 155 (85.6\%) & $218(78.4 \%)$ & $3.75(P=0.07)$ \\
\hline Program "goodie" character & $636(97.2 \%)$ & 172 (95.6\%) & 277 (99.6\%) & $3.10(P=0.15)$ \\
\hline \multicolumn{5}{|l|}{ Age } \\
\hline Child & $149(30.3 \%)$ & $6 \mathrm{I}(36.5 \%)$ & $36(26.9 \%)$ & $3.18(P=0.08)$ \\
\hline Teen & $89(18.1 \%)$ & $30(18.0 \%)$ & 0 & $25.7(P<0.00 \mathrm{I})^{*}$ \\
\hline Adult & $157(32.0 \%)$ & $43(25.7 \%)$ & $70(52.2 \%)$ & $22.2(P<0.00 \mathrm{I})^{*}$ \\
\hline Combined child/teen/adult & $96(19.6 \%)$ & 33 (19.8\%) & $28(20.9 \%)$ & $0.06(P=0.89)$ \\
\hline \multicolumn{5}{|l|}{ Ethnicity } \\
\hline Caucasian & $400(81.8 \%)$ & 140 (84.3\%) & $94(70.1 \%)$ & $8.70(P=0.005)^{* *}$ \\
\hline African & $9(1.8 \%)$ & $3(1.4 \%)$ & $\mathrm{I}(0.7 \%)$ & $0.63(P=0.63)$ \\
\hline Asian & $9(1.8 \%)$ & $5(3.0 \%)$ & 0 & $4.10(P=0.07)$ \\
\hline Hispanic & $3(0.6 \%)$ & $2(1.2 \%)$ & $\mathrm{I}(0.7 \%)$ & $0.16(P=0.99)$ \\
\hline Combination of two or more of the above & $68(13.9 \%)$ & $16(9.6 \%)$ & $38(28.4 \%)$ & $17.6(P<0.00 \mid)^{*}$ \\
\hline \multicolumn{5}{|l|}{ Weight status } \\
\hline Nonoverweight & $433(86.9 \%)$ & $154(89.5 \%)$ & 97 (72.4\%) & $15.0(P=0.00 \mathrm{I})^{*}$ \\
\hline Overweight & $19(3.8 \%)$ & $10(5.8 \%)$ & $5(3.7 \%)$ & $0.70(P=0.44)$ \\
\hline Combined nonoverweight/overweight & $46(9.2 \%)$ & $8(4.7 \%)$ & $32(23.9 \%)$ & $24.5(P<0.001)^{*}$ \\
\hline
\end{tabular}

Notes: The comparison undertaken is between RTE and BBC programming during the recording period where both channels depicted children-specific programming $(6 \mathrm{am}-1 \mathrm{I} .30 \mathrm{am})$. Values given are frequencies (total relative \%). The level of significance is represented as $* P<0.00 \mathrm{I}$ and $* * P<0.0 \mathrm{I}$.

Abbreviations: RTE, Radió Teilifís Éireann; BBC, British Broadcasting Corporation.

motivated cues, while $\mathrm{BBC}$ had a significantly higher proportion of celebratory/social $(P<0.001)$ and excitement $(P<0.001)$ motivated cues. Negative outcomes were more common on Irish television (BBC 9.0\%; RTE 18.8\%; $P=0.03$; Table 3).

\section{Discussion}

To our knowledge, this is the first study to examine the portrayal and outcome of cues for exercise within the UK and Irish broadcasting settings. Many studies have investigated the link between childhood obesity and TV advertising, but few have studied the frequency of exercise placement within children's programs. In this study, a wide variety of exercise and activity types were depicted, and often were a central aspect within the program plot. Both the UK and Irish broadcasts included a number of filler segments, broadcast between individual programs, which mostly included sportsand exercise-related themes, further promoting exercise and physical activity. In a previous study, top-ranked prime time network programs for the $2-11$ years-old category broadcast one exercise scene every 4 minutes with only $2.5 \%$ of the total viewing time featuring exercise or physical activity. ${ }^{24}$ Our study estimated that $7.7 \%$ of screen time depicted exercise. 
Table 3 Comparison of motivating factors and outcome associated with each cue

\begin{tabular}{|c|c|c|c|c|}
\hline Cue motivations and outcomes & Overall $(n=699)$ & RTE $(n=276)$ & BBC $(n=450)$ & $\chi^{2}$ \\
\hline \multicolumn{5}{|l|}{ Motivation } \\
\hline Celebratory/social & $289(30.3 \%)$ & $60(22.9 \%)$ & $160(37.7 \%)$ & $37.1(P<0.001)^{*}$ \\
\hline Excitement & $278(29.1 \%)$ & $54(20.6 \%)$ & $157(37 \%)$ & $42.5(P<0.00 \mathrm{I})^{*}$ \\
\hline Reward & $32(3.4 \%)$ & $16(6.1 \%)$ & $2(0.7 \%)$ & $16.7(P<0.001)^{*}$ \\
\hline Punishment & $15(1.6 \%)$ & $5(1.9 \%)$ & 0 & $6.92(P=0.01)^{* *}$ \\
\hline Health & $4 \mathrm{I}(4.3 \%)$ & II (4.2\%) & $21(7.6 \%)$ & $0.86(P=0.46)$ \\
\hline Competitive & 145 (I5.2\%) & $63(24.0 \%)$ & $30(10.8 \%)$ & $30.8(P<0.00 \mathrm{I})^{*}$ \\
\hline Other & $66(6.9 \%)$ & $24(9.2 \%)$ & $29(10.4 \%)$ & $0.23(P=0.66)$ \\
\hline Unknown & 89 (9.3\%) & 29 (II.1\%) & $25(5.9 \%)$ & $3.30(P=0.08)$ \\
\hline Positive & $74.9 \%$ & $62.2 \%$ & $91.4 \%$ & \\
\hline Negative & $1.9 \%$ & $2.4 \%$ & $0.0 \%$ & \\
\hline Neutral & $23.2 \%$ & $35.4 \%$ & $6.0 \%$ & \\
\hline \multicolumn{5}{|l|}{ Outcome } \\
\hline Positive & $404(61.4 \%)$ & $111(61.3 \%)$ & 168 (60.4\%) & $0.04(P=0.92)$ \\
\hline Negative & $85(12.9 \%)$ & $34(18.8 \%)$ & $25(9.0 \%)$ & $9.38(P=0.03)^{* *}$ \\
\hline Neutral & $169(25.7 \%)$ & $36(19.9 \%)$ & 85 (30.6\%) & $6.45(P=0.0 \mathrm{I})^{* *}$ \\
\hline
\end{tabular}

The reasons for the increased exercise in our study are unclear and may involve differences in the time of broadcast and types of programs between these studies. Dancing cues were most common in our study, and mild- or moderate-intensity exercise was more common than intense exercise. Few cues involved formal sporting events or team sports. Most cues did not portray sport in a negatively competitive or painful light.

In our study, the majority of exercise cues were part of the focus of the scene and located within the foreground, consistent with previous research. ${ }^{24}$ Regardless, direct health-related content may also be influential when located in the background. ${ }^{24}$ Therefore, whether within the program foreground or background, such cues have the potential to influence exercise behavior and preference..$^{30}$ Male characters were more commonly depicted, a finding similar to a previous study. ${ }^{24}$ Girls, especially older girls, often exercise less than boys of a similar age, ${ }^{31-33}$ and thus, it may be preferable to have more exercise performed by female characters. In our study, most cues depicted exercise with a positive outcome, which may encourage positive attitudes to exercise in children.

Findings for the UK and Irish programmings were broadly similar. For both stations, between-program advertisement fillers were the program type with most exercise portrayals, suggesting that both channels were actively involved in depicting healthy exercise-related behavior. Dancing cues were the most popular activity for both channels, while there was more informal exercise broadcast on the UK programs, with more sports of higher intensity, formal sports, and team activities broadcast on Irish programming. A possible reason for this difference may be the target audience and program type, with more of the UK programs directed at children, compared to more films broadcast on RTE. The UK programming was associated with less negative outcomes and motivations for exercise cues although the overall proportion of negative outcomes and motivations for both channels was very low. This difference might be explained by more highintensity exercise cues on Irish programs, which may have negative motivations or outcomes. The popularity of highintensity native Irish sports, including hurling and Gaelic football (both team-based field games unique to Ireland and played at all age levels), might explain the more frequent high-intensity sports on Irish programming.

To date, there is a paucity of research into the portrayal of physical activity and exercise within children's programming. A previous study examined the health-related behaviors within the UK soap operas and found that for the majority of the most popular soap operas, exercise-related behavior was an infrequent event although there was an increased portrayal of physical activity in programming aimed at a younger audience. ${ }^{34} \mathrm{~A}$ further study examined food advertisements directed at African-American children and found that only $9.4 \%$ of the advertisements contained physical activity-related content, which did not reflect physical activity guidelines. ${ }^{17}$ Previous media studies have shown that children are more likely to choose energy-dense, nutrientpoor products featuring nutrient content claims and sports celebrity endorsements. ${ }^{35}$ Additionally, it has been shown that parents perceive food products as healthier when they are endorsed by a professional athlete and are more likely to purchase those products. ${ }^{36}$ 
It is difficult to measure the impact of physical activity messages on behavior. Previous research has demonstrated that when participants were exposed to exercise commercials, their caloric intake was reduced in the subsequent meal. ${ }^{37} \mathrm{All}$ participants felt more active, healthy, athletic, and in good shape after watching exercise commercials compared to control commercials. ${ }^{37}$ The effectiveness of physical activity promotion has been studied, but a feature of such studies is that although many people are aware of the health benefits of exercise, promotional media campaigns have little or no impact on exercise behavior. ${ }^{38}$ Physical activity has been shown in a previous study to be associated with a higher grade-point average, and obesity was associated with a lower grade-point average in adolescence..$^{39} \mathrm{~A}$ further study exploring the contribution of extracurricular sport and screen time viewing to personality trait stability and change during childhood showed that young children who were more active recorded more of a decrease in introversion, less of a decrease in persistence, and less of an increase in reactivity than those who were less active, while in addition, young children who continued participation in extracurricular sport had greater intraindividual stability of personality for introversion. ${ }^{40}$ These findings suggest that an active lifestyle might help to facilitate desirable personality trait stability and change during childhood. ${ }^{40}$ In addition, a more recent study suggests that television viewing was unfavorably associated with several markers of inflammation and endothelial dysfunction. ${ }^{41}$ Thus, there is emerging evidence of the value of exercise and physical activity in behavior; however, the full role of exercise and physical activity promotion within a television setting and implications on subsequent childhood behavior have yet to be fully examined, but is an exciting area of further research.

This study has limitations. Although the data presented in the current study represent television broadcasts from several seasons ago, there is little subsequent reason or legislation to suggest that broadcast content has changed in the subsequent seasons. Furthermore, our findings are consistent with previous studies. Finally, the objective of this study was to examine content of broadcasts, not the effect of this content on children -this is an area of interesting future research.

\section{Conclusion}

Our results demonstrate that exercise and physical activities are common and that health and exercise promoting segments are prominent within the UK and Irish children's programming. It is known that children already watch over the recommended television viewing times and that there are numerous references to sport and exercise within programming.
Children are susceptible to marketing within television, and thus, exercise portrayal may serve as a potential aid in fighting the obesity epidemic by encouraging physical activity. The majority of exercise cues are associated with positive outcomes and motivations, thus showing exercise and physical activity in a positive light. In addition, broadcast companies included segments between programs that portrayed exercise within a positive light and thus indicated that they are making an active effort to depict exercise and physical activity. The positive portrayal of health-related activities and physical exercise on television programming has the potential to influence behavior, particularly of younger children, and thus in the future, may be seen as an avenue to further fight the ever-increasing epidemic of pediatric obesity.

\section{Author contributions}

PS designed data collection, scored recordings, analyzed data, and drafted and revised the article. OR designed data collection, scored recordings, and analyzed data. AM recorded data, designed data collection, analyzed data, and revised the article. MH and JS were responsible for the statistical design of the study and monitoring of the data coding and statistical analysis. DL initiated the project and revised the article. WC initiated the project and revised the article. CD initiated the project, monitored data collection, and revised the article. COG initiated the project, designed data collection, implemented the trial, monitored data collection, analyzed the data, and revised the article. All authors contributed toward data analysis, drafting and critically revising the paper and agree to be accountable for all aspects of the work.

\section{Disclosure}

The authors report no conflicts of interest in this work.

\section{References}

1. Saunders T. Potential contributors to the Canadian pediatric obesity epidemic. ISRN Pediatr. 2011;2011:10. [Article ID 917684].

2. Alberti KG, Zimmet P, Shaw J. The metabolic syndrome - a new worldwide definition. Lancet. 2005;366(9491):1059-1062.

3. Weiss R, Dziura J, Burgert TS, et al. Obesity and the metabolic syndrome in children and adolescents. N Engl J Med. 2004;350(23):2362-2374.

4. Weiss R. Childhood metabolic syndrome: must we define it to deal with it? Diabetes Care. 2011;34(Suppl 2):S171-S176.

5. Crespo CJ, Smit E, Troiano RP, Bartlett SJ, Macera CA, Andersen RE. Television watching, energy intake, and obesity in US children: results from the third National Health and Nutrition Examination Survey, 1988-1994. Arch Pediatr Adolesc Med. 2001;155(3):360-365.

6. Klesges RC, Shelton ML, Klesges LM. Effects of television on metabolic rate: potential implications for childhood obesity. Pediatrics. 1993;91(2):281-286.

7. Dietz WH Jr, Gortmaker SL. Do we fatten our children at the television set? Obesity and television viewing in children and adolescents. Pediatrics. 1985;75(5):807-812. 
8. Gortmaker SL, Must A, Sobol AM, Peterson K, Colditz GA, Dietz WH. Television viewing as a cause of increasing obesity among children in the United States, 1986-1990. Arch Pediatr Adolesc Med. 1996; 150(4):356-362.

9. Harrison K, Marske AL. Nutritional content of foods advertised during the television programs children watch most. Am J Public Health. 2005;95(9):1568-1574.

10. Henderson VR, Kelly B. Food advertising in the age of obesity: content analysis of food advertising on general market and African American television. J Nutr Educ Behav. 2005;37(4):191-196.

11. Kaiser Family Foundation [webpage on the Internet]. The Role of Media in Childhood Obesity; 2004. Available from: http://www.kff. org/entmedia/entmedia022404pkg.cfm. Accessed September 1, 2015.

12. Zhang G, Wu L, Zhou L, Lu W, Mao C. Television watching and risk of childhood obesity: a meta-analysis. Eur J Public Health. 2016;26(1):13-18.

13. Erik Landhuis C, Poulton R, Welch D, Hancox RJ. Programming obesity and poor fitness: the long-term impact of childhood television. Obesity (Silver Spring). 2008;16(6):1457-1459.

14. Committee on Communications, American Academy of Pediatrics; Strasburger VC. Children, adolescents, and advertising. Pediatrics. 2006;118(6):2563-2569.

15. Powell LM, Szczypka G, Chaloupka FJ, Braunschweig CL. Nutritional content of television food advertisements seen by children and adolescents in the United States. Pediatrics. 2007;120(3):576-583.

16. Silver Wallace L, Leenders N. Content analysis of prime-time television coverage of physical activity, 1970-2001. Am J Prev Med. 2004; 26(2):130-134.

17. Outley CW, Taddese A. A content analysis of health and physical activity messages marketed to African American children during after-school television programming. Arch Pediatr Adolesc Med. 2006;160(4): 432-435.

18. Nabi RL, Thomas J. The effects of reality-based television programming on diet and exercise motivation and self-efficacy in young adults. Health Commun. 2013;28(7):699-708.

19. Smith BJ, Bonfiglioli CM. Physical activity in the mass media: an audience perspective. Health Educ Res. 2015;30(2):359-369.

20. Bragg MA, Liu PJ, Roberto CA, Sarda V, Harris JL, Brownell KD. The use of sports references in marketing of food and beverage products in supermarkets. Public Health Nutr. 2013;16(4):738-742.

21. Taras HL, Gage M. Advertised foods on children's television. Arch Pediatr Adolesc Med. 1995;149(6):649-652.

22. Lewis MK, Hill AJ. Food advertising on British children's television: a content analysis and experimental study with nine-year olds. Int JObes Relat Metab Disord. 1998;22(3):206-214.

23. Cox R, Skouteris H, Rutherford L, Fuller-Tyszkiewicz M, Dell'Aquila D, Hardy LL. Television viewing, television content, food intake, physical activity and body mass index: a cross-sectional study of preschool children aged 2-6 years. Health Promot J Austr. 2012;23(1):58-62.

24. Byrd-Bredbenner C, Finckenor M, Grasso D. Health related content in prime-time television programming. J Health Commun. 2003; 8(4):329-341.
25. Harris JL, Sarda V, Schwartz MB, Brownell KD. Redefining "childdirected advertising" to reduce unhealthy television food advertising. Am J Prev Med. 2013;44(4):358-364.

26. Broadcasting Authority of Ireland [webpage on the Internet]. Strategy Statement 2011-2013; 2010. Available from: http://www.bai.ie/ wordpress/wp-content/uploads/BAI_Strategy_201113_v2ENG.pdf. Accessed September 1, 2015.

27. British Broadcasting Corporation [webpage on the Internet]. Broadcasting: An Agreement between Her Majesty's Secretary of State for Culture, Media and Sport and the British Broadcasting Corporation; 2006. Available from: http://downloads.bbc.co.uk/bbctrust/assets/files/ pdf/about/how_we_govern/agreement.pdf. Accessed September 1, 2015.

28. Greenberg BS, Rosaen SF, Worrell TR, Salmon CT, Volkman JE. A portrait of food and drink in commercial TV series. Health Commun. 2009;24(4):295-303.

29. Scully P, Reid O, Macken A, et al. Food and beverage cues in UK and Irish children-television programming. Arch Dis Child. 2014;99(11):979-984.

30. Belk RW, Pollay RW. Images of ourselves: the good life in twentieth century advertising. J Consum Aff. 1985;11(4):887-897.

31. Riddoch CJ, Boreham CA. The health-related physical activity of children. Sports Med. 1995;19(2):86-102.

32. Hussey J, Gormley J, Bell C. Physical activity in Dublin children aged 7-9 years. Br J Sports Med. 2001;35(4):268-272.

33. Riddoch CJ, Bo Andersen L, Wedderkopp N, et al. Physical activity levels and patterns of 9- and 15-yr-old European children. Med Sci Sports Exerc. 2004;36(1):86-92.

34. Verma T, Adams J, White M. Portrayal of health-related behaviours in popular UK television soap operas. J Epidemiol Community Health. 2007;61(7):575-577.

35. Dixon H, Scully M, Niven P, et al. Effects of nutrient content claims, sports celebrity endorsements and premium offers on pre-adolescent children's food preferences: experimental research. Pediatr Obes. 2013;9(2):47-57.

36. Dixon H, Scully M, Wakefield M, Kelly B, Chapman K, Donovan R. Parent's responses to nutrient claims and sports celebrity endorsements on energy-dense and nutrient-poor foods: an experimental study. Public Health Nutr. 2011;14(6):1071-1079.

37. van Kleef E, Shimizu M, Wansink B. Food compensation: do exercise ads change food intake? Int J Behav Nutr Phys Act. 2011;8:6.

38. Beaudoin CE, Fernandez C, Wall JL, Farley TA. Promoting healthy eating and physical activity short-term effects of a mass media campaign. Am J Prev Med. 2007;32(3):217-223.

39. Kantomaa MT, Stamatakis E, Kankaanpaa A, et al. Physical activity and obesity mediate the association between childhood motor function and adolescents' academic achievement. Proc Natl Acad Sci USA. 2013;110(5):1917-1922.

40. Allen MS, Vella SA, Laborde S. Sport participation, screen time, and personality trait development during childhood. Br J Dev Psychol. 2015;33(3):375-390.

41. Gabel L, Ridgers ND, Della Gatta PA, et al. Associations of sedentary time patterns and TV viewing time with inflammatory and endothelial function biomarkers in children. Pediatr Obes. 2016;11(3):194-201.

Diabetes, Metabolic Syndrome and Obesity: Targets and Therapy

\section{Publish your work in this journal}

Diabetes, Metabolic Syndrome and Obesity: Targets and Therapy is an international, peer-reviewed open-access journal committed to the rapid publication of the latest laboratory and clinical findings in the fields of diabetes, metabolic syndrome and obesity research. Original research, review, case reports, hypothesis formation, expert
Dovepress

opinion and commentaries are all considered for publication. The manuscript management system is completely online and includes a very quick and fair peer-review system, which is all easy to use. Visit http://www.dovepress.com/testimonials.php to read real quotes from published authors. 